\section{VdL: TA Luft im Lacksektor überflüssig}

D ie Technische Anleitung zur Reinhaltung der Luft (TA Luft) ist nach Auffassung des Verbandes der deutschen Lack- und Druckfarbenindustrie (VdL) für eine zeitgemäße Emissionsminderung im Lacksektor entbehrlich. Die Vorgaben zur Emissionsminderung der 31. Bundes-Immissionsschutz-Verordnung (31. BImSchV) entsprechen laut VdL dem Stand der Technik und setzen einen geeigneten Rahmen für die Pflichten der Lackieranlagenbetreiber zur Vorsorge gegen schädliche Umwelteinwirkungen. Das Festhalten an der TA Luft, einer "Relikt-Vorschrift aus den 80er Jahren", verursache nur Mehraufwand, der dem Umweltschutz nicht dienlich sei, so der Branchenverband. Deshalb solle die gegenwärtig laufende Revision der 31. BImSchV genutzt werden, solche Doppelregelungen im Umweltrecht abzuschaffen. Auf europäischer Ebene existieren sogenannte BVT-Merkblätter. Im für den Lacksektor gültigen Merkblatt wird nach Anwendungsbereichen der Lösemittel differenziert. Gleichzeitig beinhaltet das Merkblatt durchsatzbezogene Grenzwerte, die sich an den Möglichkeiten eines modernen, prozessintegrierten Umweltschutzes orientieren. Die 31. BImSchV setzt den Inhalt des BVT-Merkblattes laut Aussagen des VdL vollständig um. Die TA Luft weise dagegen lediglich einen Gesamt-Grenzwert für alle flüchtigen organischen Verbindungen auf, der sich am Prinzip der nachgeschalteten Emissionsminderung orientiert. Falls der Gesetzgeber die bestehende Doppelregelung zwischen der TA Luft und der 31. BImSchV nicht bereinige, würde bei der Umsetzung der europäischen Industrie-Emissionsrichtlinie (IED) in nationales Recht entgegen der Intention der IED der Aufwand für die Lackierbetriebe zusätzlich vermehrt statt abgebaut.

\title{
Germanischer Lloyd erteilt Zertifikat für Systemaufbau
}

$\mathrm{Nu}^{\mathrm{a}}$ ach über 15 Jahren Felderfahrung und Freigaben führender Windkrafthersteller, hat nun auch der Germanische Lloyd dem Systemaufbau aus Basecoat Delta-Tone und Topcoat Delta-Seal von Dörken MKS-Systeme im August 2012 das Zertifikat für den Einsatz auf Standardbolzen bei Windenergieanlagen im Onund Offshore-Bereich erteilt. Die damit beschichteten, hochfesten Verbindungs-

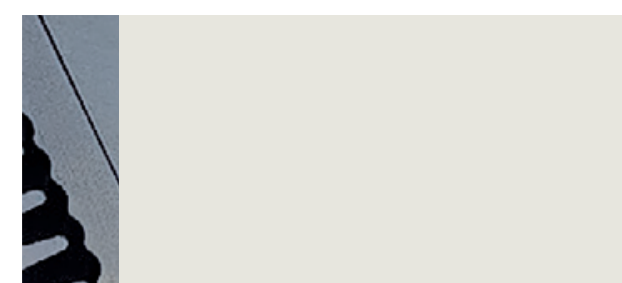

Teile-
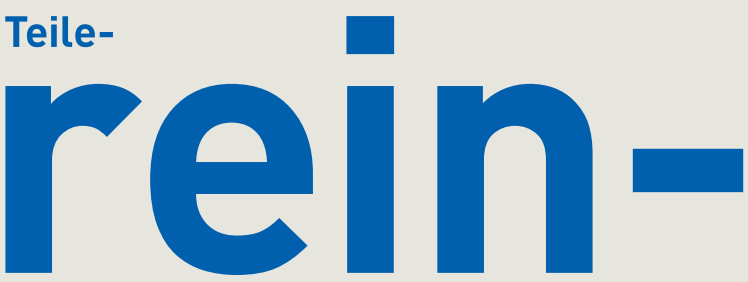

heit

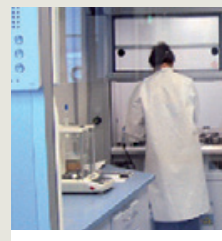

Ihr Partner für Feinreinigung

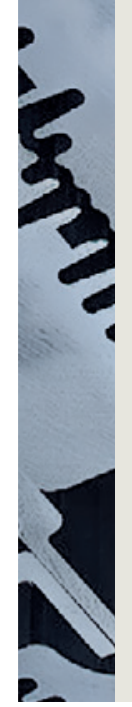

In unserem neuen, hochmodernen Kompetenzzentrum für Feinreinigung bieten wir Ihnen auf über 3000qm Fläche unterschiedlichste Verfahren mit folgenden Reinigungsmedien:

\section{- DOWCLENE (modifizierter Alkohol) \\ - wässrig (alkalisch und sauer) \\ - Kohlenwasserstoff}

Alle Anlagen sind mit Reinraumanbindung Fertigungsbegleitende Restschmutzanalysen nach VDA-Standard können im eigenen Labor durchgeführt werden.

Verlassen Sie sich auf eine termingerechte und prozesssichere Reinigungsqualität, die ihresgleichen sucht. elemente, insbesondere im Abmessungser Rotorblattverschraubung eingesetzt. Delta-Tone bietet einen aktiven kathodiSchutz und erfüllt damit auch die tweit von fast allen namhaften

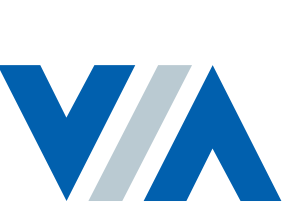

VIA Oberflächentechnik 